\title{
LA NEGOCIACIÓN EN TORNO A LA USURA EN CASTILLA, 1258-1405. ECONOMÍA, PODER Y RELIGIÓN EN LA BAJA EDAD MEDIA.
}

\author{
Octavio Colombo \\ UBA - CONICET
}

\begin{abstract}
Resumen: El tema de la usura adquiere una gran importancia en los últimos siglos de la Edad Media. El objetivo de este trabajo es analizar la negociación entre la Corona castellana y los representantes urbanos en torno a esta cuestión. Utilizaremos para ello la documentación de las Cortes entre 1258 y 1405, período en que la problemática aparece de forma recurrente y que se corresponde con la larga coyuntura depresiva de la Baja Edad Media en Castilla. Tras un análisis crítico de los conceptos de la sociología de Durkheim, se analizan las características concretas de la negociación, teniendo en cuenta tanto las coyunturas históricas específicas como las relaciones entre los distintos sectores sociales. Se evidencia así que el comportamiento de la Corona y el de los representantes urbanos se encuentra condicionado por los vínculos que los ligan a la nobleza, a los prestamistas judíos y al campesinado. El problema de la usura no puede aislarse de este conjunto más amplio de relaciones que conforman la totalidad de la estructura social feudal. En cada coyuntura particular, la reproducción de este tejido de relaciones sectoriales determina el campo de posibilidades de la negociación sobre la usura. De este modo, el análisis permite identificar, en torno a un tema particular, la forma concreta en la que opera la reproducción de la estructura social, entendida como la reproducción de las clases y facciones de clase que la conforman.
\end{abstract}

Palabras clave: Corona, Cortes, usura, campesinado, Baja Edad Media,

Abstract: The subject of usury acquires a great importance during the Middle Age's last centuries. The objective of this paper is to analyze the negotiation between the Castilian Crown and the urban representatives related to this question. We use the documentation 
of Cortes between 1258 and 1405, period of the deep depression of Late Middle Age in Castile, in which this problem was a recurrent theme.

After a critical view of Durkheim's sociological concepts, the paper analyzes the concrete characteristics of the negotiation considering the specific historical contexts and the relationships between different social sectors. This allows us to perceive that the Crown and the urban representatives' behaviors were conditioned by their ties to the nobility, the Jews moneylenders and the peasantry. Consequently, the problem of usury can't be isolated from the whole picture of relationships that form the feudal social structure. In each particular context, the reproduction of this social relation network determines the scope negotiation's possibilities on usury. Therefore, the analysis allows to identify, around a particular issue, the concrete way in which operates the reproduction of the social structure, conceived like the reproduction of the classes and factions that conform it.

Keywords: Crown, Cortes, usury, peasants, late middle ages.

\section{INTRODUCCIÓN}

El objetivo de este trabajo es analizar la negociación que se lleva a cabo en torno al problema de la usura entre la Corona castellana y los representantes de los pecheros. Intentaremos mostrar cómo dicha negociación no puede entenderse sino teniendo en cuenta sus características polifacéticas, que derivan tanto de la complejidad del vínculo que une a la monarquía con los procuradores, como de el que liga a ambos con otros actores no directamente presentes en la escena (en especial el campesinado común, los prestamistas judíos y la nobleza). La sociedad feudal, en este sentido, se presta de forma ejemplar para ser analizada como una extensa red jerarquizada de compromisos $\left\langle\right.$ totales ${ }^{1}$ entre actores cuyas relaciones sociales se concretan a través de vínculos personales directos ${ }^{2}$.

En el caso castellano, debe recordarse además que los concejos y sus representantes adquieren un gran peso político en la medida en que se convierten en un soporte financiero imprescindible para la monarquía bajomedieval. Es por ello que puede decirse que el sector dirigente de los concejos, sin ser parte de la nobleza ${ }^{3}$, cumple un papel funcional a la reproducción del vínculo feudal, en tanto materializa la percepción del tributo y la aplicación de la justicia regia. A

1. El concepto proviene de Mauss, M., «Ensayo sobre el don», en Sociología y Antropología, Tecnos, Madrid, 1979. El propio pensamiento medieval interpretaba la sociedad «como un sistema de mutuas, aunque variables, obligaciones», TAwney, R. H., La religión en el origen del capitalismo, Ed. Dédalo, Buenos Aires, 1959 , p. 30.

2. Utilizamos esta expresión por contraste con el fenómeno de la cosificación de las relaciones sociales que caracteriza a las sociedades capitalistas.

3. Astarita, C., «Caracterización económica de los caballeros villanos de la Extremadura castellano-leonesa (siglos XII-Xv)», en Anales de Historia Antigua y Medieval, n 27, Buenos Aires, 1994. 
cambio de estos servicios, la Corona gratifica a los caballeros villanos con beneficios de distinto tipo, desde la exención de tributo hasta el monopolio tendencial de los oficios concejiles.

De este sector concejil privilegiado provienen los representantes o procuradores que acuden a las Cortes. En situaciones normales, las Cortes se reúnen periódicamente, por convocatoria regia. Allí acuden los procuradores de los concejos de realengo, y presentan al monarca una serie de peticiones, sobre las cuales éste dictamina. A su vez, la Corona debe solicitar a las Cortes el otorgamiento de los llamados servicios o tributos extraordinarios (la parte normalmente mayor de las rentas reales), que en teoría sólo pueden recaudarse con el acuerdo de los procuradores.

En este trabajo analizaremos la negociación que llevan adelante los procuradores y la Corona en torno al problema de la usura, y su relación con las coyunturas socio-políticas por las que atraviesa el reino. Como veremos más adelante, además, la identificación de los usureros con los judíos da al problema una dimensión mucho más amplia que la estrictamente económica. Los términos de la negociación, variables en el tiempo, pueden reconstruirse con bastante exactitud a través de los cuadernos de Cortes, que contienen las peticiones de los representantes pecheros y las respuestas del monarca ${ }^{4}$. Lo interesante de estas fuentes es que presentan al derecho en un estado formativo, como resultado de la re-negociación permanente entre las partes. Mientras los procuradores intentan obtener respuestas favorables a sus demandas, el monarca debe cuidarse de mantener una relación cordial con ellos, si quiere contar con su apoyo político y material. Aunque la tensión del diálogo, como veremos, puede llegar a ser muy alta, en este escenario se actualiza un vínculo entre ambas partes que presenta múltiples dimensiones, y que además se complejiza -y muchas veces se contrapone- con los compromisos que cada uno ha tejido con otros actores que no se encuentran directamente presentes en la negociación.

En un sentido general, el fenómeno del endeudamiento campesino remite a la fragilidad de la reproducción de las economías domésticas sometidas a extracciones tributarias. Ello es aún más evidente en el contexto de crisis de la Baja Edad Media; los límites temporales que se proponen para este trabajo remiten

4. Cortes de los Antiguos Reinos de León y de Castilla, Real Academia de la Historia, Madrid, Tomos I-IV, 1861-1882. Se citan en adelante como Cortes, seguido del número de tomo, del año de realización de las Cortes citadas y del número de petición que corresponda. La documentación de Cortes ha sido utilizada para estudiar la evolución del antisemitismo (un tema estrechamente relacionado con el nuestro) por MonsaLVo AnTón, J. Mª., Teoría y evolución de un conflicto social. El antisemitismo en la Corona de Castilla en la Baja Edad Media, Siglo XXI, Madrid, 1985.

5. Un recorrido histórico general sobre el tema en Gelpí, R. M., y Julien-LabruYÈre, F., Historia del crédito al consumo. Doctrinas y prácticas, Península, Barcelona, 1998, 1ª Parte. 
a ella. En efecto, 1258 y 1405 son los años en que en los registros de las Cortes aparecen, respectivamente, el primero y el último de los grandes ordenamientos condenando la usura. No casualmente se trata de una cronología que se ajusta a las manifestaciones de la crisis. Desde mediados del siglo XIII, en correspondencia con el final de la gran expansión territorial cristiana hacia el sur, aparecen en Castilla síntomas evidentes de la coyuntura depresiva: procesos inflacionarios y devaluación monetaria; conflictos inter-nobiliarios; bandidismo señorial y endeudamiento campesino ${ }^{6}$. En la primera mitad del s. XIV se suman problemas climáticos y las consiguientes hambrunas por la pérdida de las cosechas; como así también los brotes de epidemia con los que tradicionalmente se asocia la crisis agraria ${ }^{7}$. Alfonso XI muere a causa de la peste, y su sucesión abre una etapa de casi dos décadas de conflictos entre facciones de la clase señorial. Las encabezan, de un lado, Pedro I, hijo legítimo de Alfonso, cuya política autoritaria y centralista le enajena rápidamente el apoyo de gran parte de la nobleza. Ésta se encuadra entonces tras Enrique de Trastámara, hermanastro de Pedro, que desde los primeros años de la década del 50 inicia una guerra civil, en la que también participarán tropas mercenarias francesas e inglesas, y que culminará hacia fines de la década de 1360 con la derrota del rey y la asunción de Enrique II al trono $^{8}$. Su triunfo, sin embargo, tendrá consecuencias sociales de gran alcance. En términos inmediatos, los ingresos para pagar a las tropas mercenarias, y la necesidad de reponer las exhaustas arcas regias, se obtienen mediante una brusca devaluación monetaria que tendrá fuertes efectos sobre la economía mercantil ${ }^{9}$, amén de una creciente imposición fiscal que se registra en las quejas de los representantes pecheros. A la vez, el apoyo nobiliario es retribuido con concesiones de mercedes que se enajenan del patrimonio real, en lo que constituye un proceso de verdadera refeudalización de la sociedad castellana ${ }^{10}$. Los conflictos políticos y sociales se continúan en las dos monarquías siguientes, las de Juan I y Enrique III,

6. Como referencia general europea puede verse el clásico artículo de PerroY, E., «A l'origine d'une Économie contractée: Les crises du XIV ${ }^{\circ}$ siècle», Annales ESC, 1949, № 2; para España, VAldeón BARUQue, J., «Aspectos de la crisis castellana en la primera mitad del siglo XIV», en Hispania, T. XXIX, n 111, 1969. RuIz, T., Sociedad y poder real en Castilla, Ariel, Barcelona, 1981, sostiene que la expansión territorial fue una causa fundamental de la crisis. Sobre el bandidismo señorial, Moreta, Salustiano, Malhechores feudales. Violencia, antagonismos y alianzas de clase en Castilla, siglos XIII-XIV, Cátedra, Madrid, 1978.

7. La descripción de una crisis de subsistencia a inicios del s. XIV en la Crónica de Fernando IV, BAE, Tomo LXVI, Madrid, 1953, Capítulo VIII, p. 119.

8. VAldeón BARuQue, J., Enrique II de Castilla: la guerra civil y la consolidación del régimen (1366-1371), Valladolid, 1966.

9. Ladero Quesada, M. Á., «La política monetaria en la Corona de Castilla (1369-1497)», en En la España Medieval, $\mathrm{n}^{\circ}$ 11, Univ. Complutense, Madrid, 1988.

10. Analizado especialmente por Clavero, B., Mayorazgo. Propiedad feudal en Castilla 1369-1836, Siglo XXI, Madrid, 1989. 
que cubren las tres últimas décadas del siglo XIV y los primeros años del XV. A partir de entonces, la reversión de la coyuntura general transforma la naturaleza del problema del endeudamiento campesino, y ello justifica el límite propuesto para este trabajo.

\section{EL ENDEUDAMIENTO CAMPESINO Y LOS USUREROS JUDÍOS}

En una primera aproximación puede afirmarse que la extracción de excedentes que realiza el capital usurario guarda una relación contradictoria con el vínculo tributario feudal, y por ende con la estructura de clases que le corresponde. Por un lado, el préstamo proporciona recursos en momentos de aguda necesidad, que permiten al campesino pechero cumplir sus obligaciones tributarias sin afectar momentáneamente su reproducción social. Por otro, sin embargo, la obligación contractual de cumplir con intereses usurarios implica para el productor una sangría de recursos que en el mediano plazo erosiona las bases de la economía doméstica, y por lo tanto, las de la fiscalidad regia.

Dicho de otro modo, el préstamo materializa la posibilidad del cobro del tributo, al tiempo que potencialmente lo hace peligrar. Esta es la contradicción material que se encuentra en la base de la negociación que se realiza entre los representantes campesinos y la Corona. Los primeros sabrán utilizarla como argumento en su favor; la segunda deberá buscar un punto de equilibrio, siempre inestable, y por ello siempre re-negociado, entre la protección del productor endeudado y la del prestamista también tributario.

Como ya hemos mencionado, además, la identificación de los prestamistas con los judíos le da al problema una dimensión confesional que se manifiesta en el plano jurídico ${ }^{11}$. En efecto, aún cuando sabemos que esto no es enteramente así, al menos desde mediados del siglo XIII les está expresamente prohibido a los cristianos prestar a interés ${ }^{12}$. En rigor, tampoco los judíos podían hacerlo con miembros de su propia comunidad: el Antiguo Testamento así lo establecía. Ello

11. Sobre la traslación jurídica de la identidad religiosa, NiREnBERG, D., Comunidades de violencia. La persecución de las minorías en la Edad Media, Península, Barcelona, 2001, p. 52. Defiende la idea de una

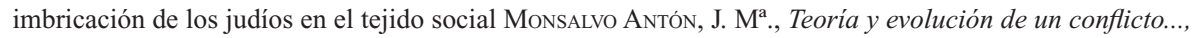
p. 38 y ss.

12. Véase infra; menciones específicas a la situación leonesa en Benito Ruano, E., «Usura y 'cambios’ en el León medieval», en Archivos Leoneses, No 47-48, 1970. Ya en el siglo XII San Bernardo había identificado a los prestamistas cristianos como «judíos bautizados», Little, L., Pobreza voluntaria y economía de beneficio en la Europa medieval, Taurus, Madrid, 1980, p. 80. Debe tenerse en cuenta, sin embargo, y contra lo que a veces se cree, que el odio a los judíos es anterior a que estos ocuparan el papel de prestamistas: «La concepción del judío demoníaco existía ya antes de la realidad del judío prestamista, y fue aquélla la que ayudó a producir ésta», CoHn, N., En pos del milenio, Alianza, Madrid 1997, p. 78. En el mismo sentido, Moore, R. I., La formación de una sociedad represora. Poder y disidencia en la Europa Occidental, 950-1250, Crítica, Barcelona, 1989, pp. 102-3. Sobre el efecto del derecho como forma de denominar y 
dio lugar al desarrollo de diversas ficciones legales que los miembros de ambas comunidades religiosas utilizaron para evadir tales restricciones; lo cual trajo aparejado, a su vez, profusas disquisiciones teológicas para establecer cuándo verdaderamente se podía considerar que la prohibición de la usura se estaba violando ${ }^{13}$.

El aspecto religioso del problema nos interesa, sin embargo, en otros sentidos. El primero de ellos es que el poder jurisdiccional de la monarquía engloba también a las minorías confesionales, y en especial a las aljamas de los judios, que aportan sustanciosos ingresos a la Corona. Su disponibilidad de capital líquido, y sobre todo la prohibición de que adquieran tierras de labranza, los obliga a dedicarse a las actividades financieras, en especial al préstamo y al arriendo de rentas reales. Convertidos así los judíos en un eslabón fundamental de la cadena de extracción feudal de excedentes, la violencia popular contra ellos puede verse, en parte, como un ataque indirecto a la monarquía; situación que obliga a esta última a darles algún tipo de protección ${ }^{14}$.

Por otro lado, sin embargo, la monarquía tiene una definición religiosa sobre la que se basa su legitimidad, y es evidente que en este plano los judíos desempeñan un rol muy distinto al que ocupan desde el punto de vista del aparato fiscal. El poder regio tiene motivos, por lo tanto, para mostrarles hostilidad en ciertas circunstancias: al interés material en garantizar la reproducción del campesinado tributario (pues la usura siempre puede convertirse en un mecanismo de extracción en competencia con la renta), se suma la necesidad política de proteger a la comunidad cristiana de la explotación a la que la someten los judios usureros, un factor que, como veremos, será utilizado en la lucha por el poder entre distintas facciones nobiliarias.

La connotación religiosa de los actores y de las relaciones económicas se presenta como un caso, original por sus particularidades, para el estudio de los mecanismos que garantizan la cohesión social. Little, por ejemplo, considera

clasificar la realidad, VILAR, P., «Historia del derecho, historia total», en Economía, Derecho, Historia, Ariel, Barcelona, 1983.

13. Grice-Hutchinson, M, El pensamiento económico en España, 1177-1740, Crítica, Barcelona, 1982, cáp. 1, «El encubrimiento de la usura», pp. 13-80. En cuanto al Antiguo Testamento, entre otras citas, véase Éxodo, XXII, 24; Levítico, XXV, 35-37; y especialmente Deuteronomio, XXIII, 20-21, que prohíbe completamente la práctica de la usura entre los israelitas.

14. Little destaca el papel en los hechos de los judíos como recaudadores reales, en tanto los impuestos que se les cobran constituyen un mecanismo de extracción indirecta sobre sus deudores, Pobreza voluntaria ...,pp. 67-8. A la vez, la dependencia de los judíos de la protección regia los convierte en víctimas predilectas de la voracidad de la Corona: véase la Crónica de Alfonso X, BAE, Tomo LXVI, Madrid, 1953, Capítulo LXXIV. Sobre la «racionalidad» de los ataques populares a los judíos, NiRENBERG señala que «la violencia de un colectivo subordinado contra otro puede constituir un acto de resistencia ante los poderosos», Comunidades de violencia..., p. 74. 
que el crecimiento de la economía monetaria entre los siglos XI y XIII «marcó el paso de lo que Durkheim ha denominado la 'solidaridad mecánica' a la 'solidaridad orgánica' ${ }^{15}$. El primero de estos conceptos remite al tipo de cohesión que existe en sociedades primitivas, no diferenciadas, donde predomina la conciencia común o colectiva por sobre la individual. La solidaridad mecánica o por semejanza, entonces, se expresa en sanciones de tipo represivo que se aplican a quienes violan normativas derivadas de fuertes sentimientos colectivos homogéneos. Por contraste, la solidaridad orgánica corresponde a sociedades evolucionadas, diferenciadas, en las que la división del trabajo ha permitido el desarrollo de la conciencia individual en detrimento de la colectiva. El derecho civil que la expresa se caracteriza por la aplicación de sanciones de tipo restitutivo, pues penaliza la violación de normas que no corresponden a sentimientos muy vivos de la colectividad, sino a «opiniones localizadas en las regiones restringidas de la sociedad», cuya contradicción sólo despierta una «reacción muy moderada» ${ }^{16}$. El desplazamiento progresivo del derecho penal (represivo) por el derecho civil (restitutivo) sería la expresión del crecimiento de la solidaridad orgánica que acompaña al incremento de la división social del trabajo.

Algunos conceptos proporcionados por este modelo sociológico tienen indiscutible utilidad para el análisis histórico. Presentados en un esquema dicotómico y excluyente, sin embargo, no tienen una aplicabilidad directa al tema de nuestro estudio. Por un lado, existen abundantes ejemplos en la documentación que muestran que el delito de usura viola sentimientos fuertemente arraigados. Tan es así que se la llega a asimilar a un delito religioso, «contra la ley divina y natural», directamente derivado del pecado capital de la avaricia. Su represión «sirve a Dios», pues los usureros «pierden su alma» al dedicarse a tal actividad ${ }^{17}$. Incluso la autoridad del Papa interviene en el caso, pues el usurero vende el tiempo, que sólo pertenece a Dios ${ }^{18}$. En el mismo sentido, la identificación del usurero con el judío, enemigo de la fe, y la prohibición absoluta para los cristianos de prestar a interés, revelaría también el tipo de cohesión por semejanza que caracteriza a la solidaridad mecánica. En el discurso jurídico, los cristianos-deudores aparecen

15. Little, L., Pobreza voluntaria..., p. 54.

16. Durkheim, E., La división del trabajo social, Akal, Madrid, 1995, p. 150.

17. Expresiones de este tenor se encuentran en todos los ordenamientos condenatorios de la usura; véase infra. Sobre la importancia que adquiere la avaricia en el discurso teológico medieval, LitTLe, L., Pobreza voluntaria..., pp. 55-6.

18. Véase al respecto el excelente ensayo sobre la usura de LE GoFF, J., La bolsa y la vida. Economía y religión en la Edad Media, Gedisa, Barcelona, 1987. También Wood, D., El pensamiento económico medieval, Crítica, Barcelona, 2003, p. 224 ss. 
sujetos a la explotación inmoral de los judíos-acreedores: la condena de la usura es también una protección a los seguidores de la verdadera $\mathrm{fe}^{19}$.

Por otro lado, sin embargo, el problema del préstamo presenta igual cantidad de caracteres que lo asimilan al tipo de vínculo propio de la solidaridad orgánica. En un sentido general y evidente, el préstamo es una obligación recíproca derivada de la división del trabajo: un actor presta un servicio -en este caso, adelanta dinero-, y el otro queda comprometido a su devolución. Se establece así un vínculo contractual y privado de naturaleza civil, que cumple con todas las características propias de la solidaridad orgánica. Las condiciones generales o externas del contrato se encuentran, por otro lado, reguladas por la normativa estatal, una condición que Durkheim considera vital para el buen funcionamiento de las obligaciones recíprocas ${ }^{20}$. Además, y esto constituye para el autor la determinación objetivamente comprobable de la naturaleza de la norma $-\mathrm{y}$ por lo tanto del tipo de solidaridad subyacente--, la sanción que se aplica en caso de violación de la normativa da lugar a la aplicación de sanciones restitutivas: el usurero debe devolver lo que ha tomado indebidamente, o lo que es lo mismo, se le impide cobrar la parte de la deuda que se presume que excede el interés legalmente permitido. Este es el caso de las llamadas quitas y esperas, que veremos en detalle más adelante ${ }^{21}$.

El problema se complica aún más porque la «reglamentación» externa del contrato es el objeto central de la negociación; sometida a una re-discusión permanente tiene, por lo tanto, una fluidez y variabilidad que es resultado de los avatares coyunturales del conflicto. Lejos de constituir una anomalía, esta no-

19. Por contraste, la apropiación de excedentes a través del tributo, mucho más onerosa, no es cuestionada; debe rescatarse en este sentido la definición de «crimen» dada por Durkheim, según la cual un acto es criminal porque viola la norma: «No lo reprobamos porque es un crimen, sino que es un crimen porque lo reprobamos», ob. cit., p. 96. La condena de la usura y la aceptación del tributo son un buen ejemplo de ello. Véase al respecto Clavero, B., Usura: del uso económico de la religión en la historia, Tecnos, Madrid, 1984 , pp. $22-4$.

20. Op. cit., pp. 250 ss.; al punto que asimila la falta de regulación con un estado «anómico» de división del trabajo, p. 431.

21. Es cierto que la usura puede considerarse una forma anómala de «división coactiva del trabajo», puesto que las condiciones externas de la competencia no están igualadas, y el contrato no es entonces realmente libre. Sin embargo, en este caso deberíamos concluir que la forma no-anómala no existe en las sociedades de clases; como señala el autor, «no puede haber ricos y pobres de nacimiento sin que haya contratos injustos», ob. cit., pp. 450-1. En el límite, ningún contrato sería «libre», cuanto más no sea porque todo contrato supone que una de las partes tiene lo que la otra necesita y viceversa, lo cual implica una suerte de «coacción mutua» (y ello porque la libertad no es, como decía Hegel, el antónimo de la necesidad, sino la conciencia de ésta). Durkheim confunde, además, el consentimiento libre con el intercambio de equivalentes («el contrato no se halla plenamente consentido sino cuando los servicios cambiados tienen un valor social equivalente», p. 449), cuando bien puede ocurrir que un intercambio de equivalentes se realice sin libertad de las partes y dé lugar además a una apropiación de valor -como ha mostrado Marx con respecto al valor de la fuerza de trabajo, la coacción económica subyacente y la extracción de plusvalía a la que da lugar. 
cristalización de la reglamentación (que se corresponde con la forma personal y directa de las relaciones sociales) es la mejor vía para acceder al carácter históricamente específico no sólo del derecho ${ }^{22}$, sino también de la posición de los actores y de los vínculos que los unen -vínculos normalmente tensos, suficientemente fuertes como para garantizar la reproducción social, aunque no tanto como para evitar su ruptura en circunstancias puntuales.

Esta dificultad que se presenta para encuadrar el objeto de este estudio en alguno de los tipos sociales ideados por Durkheim cuestionaría la correspondencia estrecha que establece el autor entre sanción, sentimiento violado, y forma de solidaridad social subyacente (represivo-conciencia colectiva-solidaridad mecánica, por un lado; restitutivo-conciencia individual-solidaridad orgánica, por otro $)^{23}$. Es por ello más conveniente, para nuestros fines, enfocar el problema utilizando algunos de estos conceptos pero en el marco de un análisis general de los compromisos concretos, materiales y simbólicos, contraídos por los sujetos sociales, y de la forma en que tales obligaciones condicionan el accionar de éstos frente a la cuestión del endeudamiento campesino.

\section{LOS COMPROMISOS DE LOS ACTORES}

El cuadro global de los actores que intervienen en la negociación, su definición jurídica y sus relaciones mutuas, puede entonces presentarse de la siguiente forma.

22. Que se asemeja de este modo a los que WeBer denomina la «justicia del Cadí», la cual opera «de un modo no formal y de acuerdo con juicios de valor éticos concretos o de otra índole práctica», por oposición a la que se basa en normas jurídicas formales rigurosamente definidas, Economía y Sociedad, FCE, Bogotá, 1944, p. 732. En los términos de BouRdieu, el campo jurídico no aparece como una esfera autonomizada que se interpone como mediadora entre las partes directamente involucradas en el conflicto; véase especialmente su artículo «La fuerza del derecho», en Poder, derecho y clases sociales, Editorial Desclée de Brouwer, Bilbao, 2000.

23. En algunos casos ni siquiera parece tan evidente la diferencia entre sanciones represivas y restitutivas: la vendetta, por ejemplo, caso clásico de venganza represiva en sociedades primitivas, puede verse también como una restitución del honor para el clan agredido. Además, las penas a veces confluyen o se yuxtaponen. La prisión por no pagar el tributo, que se aplica en la Edad Media, es una sanción represiva que opera como sustituto último y secundario ante la imposibilidad de una sanción restitutiva, cuando el deudor es insolvente; en el mundo antiguo, por el contrario, la servidumbre o esclavitud por deudas tiene un contenido restitutivo. En la actualidad, el robo o la estafa son delitos penales, pero dan lugar a una demanda civil restitutiva cuando afectan a una persona física o jurídica. La única regla parece ser, en realidad, que la sanción restitutiva se aplica siempre que es posible, más allá de que el delito sea, además, pasible de una sanción represiva o no. Si la aplicación diferencial de cada tipo de sanción (o de ambas) no es tan diáfana como pretende Durkheim en tanto expresión de la naturaleza del delito, resulta algo osado deducir de ellas el tipo de sentimiento violado y el tipo de solidaridad subyacente. Señalemos por último que estas dificultades no son ajenas a la matriz kantiana en la que se inscribe el trabajo de Durkheim: «En esta tradición idealista, la objetividad del sentido del mundo se define por el acuerdo de las subjetividades estructurantes», BouRDIEU, Poder, derecho..., p. 90. 
El diálogo que nos descubren las fuentes se realiza entre las peticiones de los representantes concejiles y las respuestas que da el monarca. Los primeros cuentan con privilegios materiales y simbólicos que los ligan a la reproducción del poder; su lenguaje normalmente deferente es expresión de ese vínculo. Al mismo tiempo deben, sin embargo, obtener soluciones, o al menos paliativos, para la situación de sus representados (en el caso que nos ocupa, su situación de endeudamiento): aunque sean el estrato superior de la comunidad, no son una casta cerrada que ejerza un dominio absoluto sobre ella ${ }^{24}$. No son funcionarios regios, entonces, pero tampoco pueden tomarse sus declaraciones como expresión directa de las opiniones o demandas del campesinado común. Su función de mediadores para la materialización del vínculo entre el poder central y la base tributaria les crea compromisos en ambas direcciones.

El monarca, por su parte, también tiene un margen de acción estrecho. Por razones materiales y de legitimación, debe ser permeable a las peticiones que se le hacen: la percepción de tributos en el corto y mediano plazo, en especial de los extraordinarios, depende de ello. No puede, sin embargo, condenar de manera irremediable a los prestamistas judíos: éstos le proveen ingresos directamente -a cambio de privilegios y protección-, pero también indirectamente- mediante préstamos con los que el campesinado concreta el pago de tributos. Dicho de otro modo, las obligaciones, jugosamente retribuidas, que contrae con la comunidad judía, estrechan, en diverso grado según la coyuntura, su capacidad de maniobra. Otro tanto le ocurre, en ciertas circunstancias, en su relación con la clase señorial: debe proteger sus intereses, pero también debe atender las quejas que por ellos presentan los representantes del común. Desde este punto de vista, entonces, la Corona aparece también como mediadora, posición que resulta, no de una dilución de su carácter de clase, sino de la negociación permanente a la que la obligan las condiciones de reproducción del vínculo feudal.

La negociación se realiza, entonces, en un contexto de aguda crisis social, entre dos actores. Como en toda negociación, cada parte intenta obtener concesiones de la otra; pero cada una debe, al mismo tiempo, respetar en cierto grado compromisos contraídos con otros actores que no se encuentran directamente presentes en la escena. La reproducción global del sistema en el mediano lazo no es más que una composición de estas lógicas sectoriales.

24. Aun aquellos autores que identifican a los caballeros villanos con la clase señorial reconocen que el poder concejil no es «un coto cerrado en manos de las oligarquías», y enfatizan la importancia de los mecanismos de su «legitimación ideológica» ante el común; Martín CEA, J. C., y BonachíA, J. A., «Oligarquías y poderes concejiles en la Castilla bajomedieval: balance y perspectivas», en Revista d' Història Medieval, $\mathrm{n}^{\circ} 9$, Valencia, 1998, pp. 30 y 33. 
Veamos las características concretas que adquiere la negociación en cada coyuntura.

\section{UN SIGLO DE COMPROMISOS VARIABLES (DE MEDIADOS DEL XIII A MEDIADOS DEL XIV)}

Los lineamientos generales del tratamiento jurídico de la cuestión de la usura (la «regulación estatal» de los contratos privados mencionada por Durkheim) son establecidos tempranamente, en la segunda mitad del XIII, por Alfonso X y Sancho IV ${ }^{25}$. De forma resumida son los siguientes: los cristianos no pueden prestar a interés; judíos y moros pueden hacerlo a un $33 \%$ anual ( $a$ tres por quatro $)^{26}$, hasta que el monto de intereses o logro acumulado iguale a la suma original o principal; las cartas de deuda caducan a los 6 años; judíos y moros no pueden tener tierras de labranza. Estos ordenamientos, sobre todo los de Alfonso El Sabio, constituyen la matriz de la legislación posterior, innumerables veces citados como forma de legitimación por los monarcas sucesivos, aunque innumerables veces también modificados en diversos aspectos según las coyunturas.

La distinción que así se establece entre judíos-prestamistas y cristianos-deudores es una suerte de profecía auto-cumplida: los judíos se convierten en prestamistas por la doble restricción legal que les impide a ellos adquirir tierras y a los cristianos prestar a interés ${ }^{27}$. Dicho esto, el primer elemento que se destaca en la normativa es el intento de limitar en el tiempo el vínculo de dependencia creado por el préstamo. En efecto, a la tasa de interés fijada, la condición de que el logro iguale al principal se cumple a los tres años; a partir de ese momento, en teoría, el monto de la deuda se congela. La cláusula según la cual toda carta de préstamo caduca a los 6 años (es decir, no puede ser demandada a partir de ese tiempo), no tiene entonces el objetivo económico de limitar el crecimiento desmesurado de las deudas, sino el de romper un vínculo entre deudor y acreedor

25. Cortes, I, 1258, pet. 29-30; 1268, pet. 44; 1293, pet. 23-24. Véase también Barrios García, A., Expósito, A. M., del Ser Quijano, G. (eds.), Documentación medieval del Archivo Municipal de Alba de Tormes, Salamanca, 1982, doc. 6, 1/5/1260.

26. Éste no debe considerarse, sin embargo, un límite superior inviolable: el concejo y la aljama de Cuenca, por ejemplo, acuerdan un interés del 40\% en 1318; F. A. ChaCón Gómez-Monedero (ed.), Colección diplomática del Concejo de Cuenca, 1190-1417, Cuenca, 1998, doc. 51, 18/9/1318. Conviene aclarar también que, aunque los moros son formalmente mencionados junto a los judíos en los ordenamientos, la discusión en torno a la usura gira exclusivamente en torno a estos últimos; ese será, por lo tanto, el eje de nuestro análisis.

27. No por ello, sin embargo, la dicotomía deja de ser extremadamente abusiva. Clavero señala que la prohibición de derecho se combina con una tolerancia de hecho, Usura: del uso económico..., p. 41. Se mencionan casos de cristianos prestamistas en Cortes, I, 1258, pet. 29, 1348, pet. 2; II, 1373, pet. 9; 1377, pet. 5. También se denuncia que los cristianos utilizan a los judíos como testaferros para dar a usura en Cortes, I, 1315 , pet. $25 ; 1322$, pet. 55 . 
que podría transformarse en permanente. En efecto, aun una deuda congelada, pero impaga, crea una relación de dependencia cuyas formas concretas escapan a la documentación conservada, pero que es fácil imaginar que interfiera en el vínculo excluyente que la Corona intenta mantener con el campesinado tributario. Los prestamistas, de hecho, intentan eludir esta limitación mediante la renovación de las cartas, una práctica frecuentemente denunciada. El poder es también permeable, por otro lado, a las necesidades de los acreedores: en 1301 por rrazón dela guerra el plazo para las cartas vigentes se alarga de 6 a 9 años ${ }^{28}$.

Pero el punto en torno al cual se revelan muy tempranamente los límites a los que deben adecuarse las decisiones monárquicas es la discusión sobre los alcaldes o entregadores apartados. La cuestión refiere a si los judíos deben o no tener un funcionario de justicia especial, distinto a las autoridades del concejo («apartado»), para que libre los pleitos por deudas que ellos tienen con los cristianos. Este es un privilegio de la comunidad judía que los representantes pecheros atacan con frecuencia: se trata, sin duda, de un elemento clave para agilizar la devolución de los préstamos. En 1293, Sancho IV intentó conformar a ambas partes, estableciendo que no hubiera alcaldes apartados, pero que un miembro del concejo librara «apartadamente» los pleitos de los judíos, en manera quelos christianos ayan su derecho et los iudios el ssuyo, y que non rreçiban los iudios alongamiento por que sse detenga el pecho que me ouieren adar ${ }^{29}$. En 1299 se repite la disposición, para que los judíos ayan bien paradas sus debdas, e puedan a mi conplir los mios pechos ${ }^{30}$. La medida no contempla más que de forma retórica, evidentemente, la demanda de los procuradores. Éstos la repiten dos años más tarde, ocasión en la que el monarca se muestra sinceramente explícito: reconoce haber puesto entregadores apartados por que pedia yo el pecho delos judios que non podian auer los judios sus debdas, y agrega hablando de forma indirecta a los prestamistas: que assi commo ellos quieren queles tenga yo lo queles prometi, queme tengan ellos lo queme otorgaron e lo que prometieron ${ }^{31}$.

Difícilmente podría el rey expresar de forma más clara el compromiso que ha adquirido y el interés que lo motiva. Su actitud ha sido, sin embargo, demasiado unilateral -casi exclusivamente centrada en garantizar las condiciones que permiten a los judíos pagar el tributo-; el agravamiento de la crisis lo obligará a corregirla. Los procuradores, por su parte, ante la relativa impermeabilidad del poder, comienzan a ensayar argumentos más duros. En 1307, vuelven a plantear

28. Cortes, I, 1301, pet. 10; el alcance de la medida debió ser aclarado en las Cortes siguientes, realizadas en Medina del Campo, véase Documentación... Alva de Tormes, doc. 24, 1/6/1302, p. 71.

29. Cortes, I, 1293, pet. 25.

30. Cortes, I, 1299, pet. 11.

31. Cortes, I, 1301, pet. 9. 
el tema de la usura y piden arribar a un acuerdo en guisa que non venga dellos [los judíos] tanto mal commo viene nin se astrague dellos la tierra commo se astraga, una alusión evidente al rol protector que debe asumir el monarca con el campesinado tributario $^{32}$. La respuesta que obtienen no es del todo alentadora: se establece genéricamente que deben respetarse los ordenamientos de Alfonso X y Sancho IV ${ }^{33}$.

El endurecimiento del discurso de los procuradores, cuya ineficacia negociadora probablemente los pusiera en una situación incómoda frente a los peche$\operatorname{ros}^{34}$, se amplía hacia otros aspectos y va adquiriendo un matiz manifiestamente xenófobo. En las Cortes de las primeras décadas del siglo XIV, las peticiones relacionadas con la usura se presentan en bloque junto con otras de tipo discriminatorio y segregacionista hacia las minorías religiosas; solicitan, en el mismo sentido, que se aplique la bula papal de excomunión a usureros cristianos ${ }^{35}$. Esto puede considerarse el resultado lógico de tres factores conexos: la representación confesional del problema de la usura impuesta desde mediados del s. XIII, la incapacidad de la Corona para dar respuestas concretas al problema, y el agravamiento de la crisis social a medida que se acercan las décadas centrales de la centuria.

Los procuradores se empeñan, en adelante, en perfeccionar esta línea discursiva. A la enumeración de las calamidades que afectan a los $\operatorname{cristianos}^{36}$, con la velada presión moral que ello implica para la Corona, se suma en 1339 un argumento clave: si los campesinos tuvieran que pagar todas sus deudas con los judíos perderian lo que an e non podrian conprir los vuestros pechos ${ }^{37}$. El recurso no es del todo ineficaz: Alfonso XI responde quelos judios le fazzen agora seruiçio para este mester granada mente, pero catando el seruiçio quele agora ffazen los dela ssu tierra, otorga una moratoria de un año para todas las deudas. El monarca explicita de esta forma su disposición a privilegiar el vínculo que lo une a los procuradores, actitud tanto más valorable en tanto implica sacrificar parcialmente la relación con otro actor que también «le hace servicio». Pocos

\footnotetext{
32. Cortes, I, 1307, pet. 28.

33. El problema es que el monarca otorgaba, por otro lado, cartas en contrario, como se menciona por ejemplo en Cortes, I, 1312, pet. 100; 1318, pet. 4.

34. Debe también tenerse en cuenta que el debilitamiento de la capacidad de los pecheros para tributar sin duda tenía un efecto perjudicial sobre la percepción de las rentas municipales, es decir, aquellas directamente controladas por las aristocracias locales.

35. Medidas segregacionistas en Cortes, I, 1313, pet. 26-9, 1315, pet. 24, 1322, pet. 54; pedidos de excomunión en 1313 , pet. 21 .

36. Por ejemplo en Cortes, I, 1325, pet. 14.

37. Cortes, I, 1339, pet. 13.
} 
años más tarde, en las Cortes de Burgos de 1345, los procuradores despliegan una nueva ofensiva: sostienen que los cristianos están muy pobres por rrazon delos nuestros pechos queles rrecreçieron de poco tienpo aca para nuestro seruiçio, y por eso no pueden pagar las deudas con los judíos, lo que responsabilizaría indirectamente al monarca por el endeudamiento campesino ${ }^{38}$.

El tono crecientemente beligerante de los representantes concejiles, expresión de la creciente gravedad del problema, obliga a un reacomodo del poder regio. Incapaz de romper de forma tajante sus acuerdos con la comunidad judía (materializados en la concesión de privilegios a cambio de tributos, arrendamiento de rentas y otros servicios técnicos y financieros), la Corona intentará sin embargo, desde las primeras décadas del XIV, dar algún tipo de paliativo concreto a la situación de los campesinos endeudados. El cambio de actitud se corresponde, no casualmente, con un período de regencia del reino a causa de la minoridad de Alfonso XI (que se prolonga de las Cortes de 1313 a las de 1325, en que el monarca asume personalmente), clásica situación en la cual la legitimidad simbólica del poder feudal se ve fuertemente debilitada ${ }^{39}$. Ciertas concesiones son entonces inevitables ${ }^{40}$.

En efecto, es en 1315 cuando tenemos registro de la primera quita ordenada en Cortes para los deudores de todo el reino; en adelante éste será el eje en torno al cual girará la discusión de la usura en el siglo XIV. El mecanismo de la quita es simple: el rey decreta una reducción determinada, normalmente de un cuarto o un tercio, de los montos adeudados al momento. La medida puede ir acompañada por un período de moratoria o espera, en el que se congela la generación de intereses, lo cual constituye una suerte de «quita a futuro» (sobre los intereses que, en caso de no haber espera, se sumarían al monto total adeudado).

La quita es el tipo característico de sanción restitutiva, en el sentido planteado por Durkheim, que se aplica frente a la usura. La medida se justifica, en efecto, porque se denuncia que los prestamistas violan la normativa vigente dando a mayores intereses que los permitidos (a más de tres por quatro), o bien consignan en las cartas de obligación sumas mayores a las efectivamente prestadas (cartas

38. Cortes, I, 1345 , pet. 5 .

39. Monsalvo Antón, J. Ma ., La Baja Edad Media en los siglos XIV-XV. Política y cultura, Editorial Síntesis, Madrid, 2000, p. 24. La Crónica de Alfonso XI, B. A. E., Madrid, 1953, Capítulo XXXVII, p. 197, describe las negativas consecuencias del largo período de minoridad.

40. El concejo de Ledesma consideraba que la confirmación hecha por el tutor de los ordenamientos sobre las deudas de los judíos es una de las cosas que más cunple a esta tierra, Expósito, M. A., Monsalvo Antón, J. Ma . (eds.), Documentación medieval del Archivo Municipal de Ledesma, Salamnca, 1986, doc. 20, 20/5/1322, p. 61 . 
por el doblo $)^{41}$. Los cristianos-deudores, a su vez, se ven obligados a aceptar tales fraudes por lo apremiante de su situación, causada en parte, como ya se ha visto, por el incremento de los tributos regios ${ }^{42}$. El carácter restitutivo de las quitas, entonces, se deduce de la presunción de que los montos adeudados que se consignan en los contratos individuales superan el interés legalmente establecido.

Más importante aún, sin embargo, es que las quitas van invariablemente acompañadas de la siguiente condición: que en determinados plazos, en general menores a un año, se pague el resto de la deuda; en caso contrario, el deudor no será beneficiado por la reducción del monto. Esta cláusula tiene un doble significado. Por un lado, intenta dar una solución definitiva al problema de las deudas acumuladas, cortando de manera tajante el círculo vicioso que tiende a convertir al endeudamiento en permanente. Aparece aquí nuevamente la preocupación por la duración del vínculo que ya hemos mencionado antes: la Corona tiene especial interés en terminar con estas formas de "solidaridad orgánica» que interfieren en la relación de dependencia feudal. A cambio de la reducción, el campesino debe pagar en un plazo relativamente corto. Beneficiado por un rápido cobro, el prestamista debe aceptar en compensación la reducción. Se trata de una situación límite de vencimiento impago de las obligaciones, en la cual el monarca intenta equilibrar los intereses en pugna. Por otro lado, aunque la efectividad de la medida es discutible ${ }^{43}$, su efecto simbólico es indudable: se trata de una medida concreta, tangible, que no se limita a repetir de forma genérica añejos ordenamientos que nadie cumple, sino que establece una modificación real en los términos de los contratos existentes.

Este reacomodamiento de la política regia, sin embargo, no hace olvidar al monarca de sus compromisos con los prestamistas. En muchas ocasiones, y de forma sólo en apariencia contradictoria, las quitas van acompañadas por distintas medidas que les brindan importantes garantías de cobro. Unos pocos ejemplo sirven de ilustración: en 1315, se establece una reducción de un tercio de las deudas, pero al mismo tiempo se condena a quien intente evadir el pago de sus obligaciones amparándose en la bula papal contra la usura, y se manda a las au-

41. Las violaciones a la norma se derivan de la «complicidad inicial que el usurero puede lograr del prestatario, dada su necesidad económica en el momento de la solicitud y concesión del préstamo», Clavero, B., Usura: del uso económico..., p. 43.

42. En 1349, los procuradores de León manifiestan de forma muy clara esta responsabilidad indirecta de la Corona, por contraste con la ilimitada devoción de los campesinos por ella: declaran que los cristianos aceptan los engaños a que los someten los judíos por la priesa que tenian de nos seruir; Cortes, I, 1349, pet. 11.

43. Pues es improbable que al menos los deudores en peor situación pudieran liquidar sus obligaciones, incluso reducidas, en plazos tan breves. La medida tal vez era más eficaz en beneficio de las elites concejiles endeudadas, estrato social del que provienen los procuradores, que contaban con mayores posibilidades (por su manejo de los recursos del concejo) de acceder a fondo líquidos con rapidez. 
toridades judiciales que pongan a recaudo los bienes y heredades de los deudores en juicio para que el christiano quela non venda nin la malmeta nin fagga ssobrello ningun enganno porque el judio pierda lo ssuyo ${ }^{44}$. En 1325, una reducción de un cuarto de las deudas se acompaña de cláusulas similares, según se declara, por quelos judios me querellaron ${ }^{45}$.

En adelante, la tensión del diálogo entre la Corona y los representantes pecheros pasa por el monto de las quitas y la duración de las esperas. La tendencia es a que el monarca conceda menos de lo solicitado, pero conceda algo: son los casos de 1325, 1329, 1339 y1345 ${ }^{46}$. Ya hemos visto cómo, paralelamente, va subiendo el tono de los reclamos. La negociación discurre, entonces, en un equilibrio tanto más precario, en tanto se agrava la situación socio-política del reino. A partir de los años finales de la década de 1340, el conflicto adquiere una nueva y cada vez más sombría fisonomía.

\section{EL AGRAVAMIENTO DE LA CRISIS Y LA RUPTURA DEL COMPROMISO (SEGUNDA MITAD DEL XIV)}

Uno de los últimos y más importantes actos legislativos de Alfonso XI fue el llamado Ordenamiento de Alcalá de 1348. Este corpus jurídico contiene varios capítulos referidos al tema de la usura, con una innovación trascendente: tras declarar su carácter herético, por primera vez se prohíbe totalmente que moros y judíos presten dinero a interés, y se les permite comprar tierras de labranza en la jurisdicción regia, por un monto determinado, para que puedan mantenerse ${ }^{47}$. Se declara, al mismo tiempo, a la comunidad judía bajo guarda y deffendimiento real, y se les garantizan todos sus otros privilegios ${ }^{48}$. Esta drástica medida debe interpretarse en su contexto: se toma en el inicio de lo que será el período más crítico de la crisis social. A los brotes de epidemia y a los trastornos climáticos recurrentes, debe agregarse la prolongada guerra civil que se desatará en Castilla por el acceso al poder entre distintos sectores nobiliarios. La prohibición taxativa de usura es tan imposible de cumplir en términos reales, como representativa en términos simbólicos del comienzo de un período de resquebrajamiento relativo de la red de compromisos que hasta este momento, mal que bien, se había mantenido.

\footnotetext{
44. Cortes, I, 1315, pet. 28 y 30, respectivamente; esta última se repite en 1322, pet. 59.

45. Cortes, I, 1325, pet. 14 .

46. Cortes, I, 1325, pet. 14; 1329, pet. 52; 1339, pet. 13; 1345, pet. 4; en estos dos últimos casos, sólo se otorga espera, sin quita.

47. Cortes, I, Ordenamiento de Alcalá de 1348, cáp, LV y LVII.

48. Cortes, I, 1348, pet. 54.
} 
Muerto Alfonso en 1350 a causa de la peste, lo sucede en el trono su hijo Pedro I, quien pretende desplegar un proyecto de poder centralista que excluye las formas en las que se venía realizando el diálogo y la negociación. Las únicas Cortes de las que se conserva documentación convocadas en los 19 años que dura su reinado son las de 1351, y su línea de conducta ya se manifiesta allí de forma evidente. Ante el pedido de espera que le realizan los procuradores, el monarca responde que non es mio seruiçio nin pro delos dela mi tierra ${ }^{49}$. Los representantes concejiles replican, entonces, en tono más impreciso y moderado, pidiendo alguna manera para que los campesinos puedan pagar los préstamos a los judíos de forma tal que al mismo tiempo quelos judios ouiesen vida e pasada entrellos. La respuesta regia es casi brutal: establece que los judíos tengan entregadores apartados (privilegio que había sido abolido en 1348) pues ellos non son omes sabidores de fuero nin de derecho et otrosi porque son omes de fraco poder, y otras medidas para que los deudores no los lleven a pleito maleçiossa miente ${ }^{50}$. Estas actitudes, junto con el nombramiento de Samuel el Levi, judío prestamista, como tesorero del rey, fueron hábilmente utilizadas por la fracción nobiliaria encabezada por Enrique de Trastámara, que desarrolló una propaganda de corte xenófobo contra la supuesta tendencia filo-judía del monarca.

No es necesario, sin embargo, atribuir a Pedro I tales simpatías para comprender su accionar ${ }^{51}$. Más bien pareciera que el monarca intenta desprenderse de todo condicionamiento, y en primer lugar del que le generan las demandas de los procuradores, representantes de la base de apoyo fundamental de la Corona. La misma política, frecuentemente materializada en homicidios sólo en apariencia arbitrarios, despliega el rey frente a algunas facciones nobiliarias, que rápidamente pasan a engrosar las filas del bando rival. Mientras tanto, Pedro construye un círculo íntimo de adictos, a quienes encumbra en puestos claves de poder, y se apoya en sectores privilegiados de la comunidad judía, cuyo atractivo para la monarquía radica en su relativa insignificancia política y en su manejo de cuantiosos recursos financieros ${ }^{52}$. El proyecto centralista - una aspiración por

49. Cortes, II, 1351, pet. 75 .

50. Ídem, pet. 76. Como señala Monsalvo Antón, pocas veces los procuradores fueron «tan contrariados por un rey en la cuestión judía», Teoría y evolución de un conflicto..., ob. cit., p. 234.

51. De hecho, cuando los procuradores le pidieron que los judíos pudieran dar a usura y no comprar heredades, como antes del ordenamiento de 1348, el rey respondió vagamente que examinaría el caso, tal vez preocupado por la disminución que ello podría suponer en las rentas agrarias; Cortes, II, 1351, pet. 66. La demanda es en sí misma reveladora: los representantes pecheros comprendieron muy rápidamente que la eliminación completa del préstamo generaba más problemas que soluciones, una prueba más del carácter objetivamente ineludible de la relación de endeudamiento.

52. Monsalvo Antón, J. M., Teoría y evolución..., p. 231. 
otro lado recurrente en la Corona castellana ${ }^{53}$ - no era entonces del todo banal, como aparece retrospectivamente tras su estrepitoso fracaso. Se basaba lisa y llanamente en una re-configuración profunda de los compromisos de la monarquía, tendiente a garantizarle un alto grado de autonomía frente a los actores más relevantes: los concejos y la nobleza.

El bando opositor al rey, por su parte, se presenta como el restaurador de un orden violentado, y explotará en su favor la torpeza que despliega el monarca en la persecución de sus intereses. La propaganda anti-judía es un buen ejemplo de ello, pues permite a la fracción encabezada por Enrique responder a un problema materialmente muy sentido por los pecheros (e incluso por sus elementos dirigentes), y al mismo tiempo negarle al monarca la legitimidad que le correspondería si actuara como un verdadero rey cristiano.

Pero Enrique se maneja, al mismo tiempo, de forma tan pragmática como la situación se lo exige: si pasamos del terreno de la propaganda al de los hechos, su accionar es mucho más mesurado. Es cierto que muchas aljamas fueron atacadas por las tropas del Trastámara durante la guerra ${ }^{54}$, y también que Enrique toleró o incluso alentó tales agresiones porque las gentes lo facían de buena voluntad, e por el fecho mesmo tomaban miedo e recelo del rey [Pedro] e tenían con el conde [Enrique] ${ }^{55}$. Sin embargo, a medida que se va acercando su triunfo, el futuro rey comienza a modificar esta conducta y se muestra proclive a llegar a una concordia con la comunidad judía, a cambio de lealtad $y$, sobre todo, de cuantiosas sumas de metálico. Es así como en 1366 la judería de Burgos le otorga un servicio de un millón de maravedíes, que Enrique reparte hábilmente con todos los que venían con él $l^{56}$; otro tanto hace la aljama de Toledo, dinero utilizado con el mismo fin ${ }^{57}$. La ciudad de Burgos, sin embargo, vuelve rápidamente a ser controlada por los partidarios de Pedro I; cuando Enrique la recobra para sí en 1367, la judería primero se resiste, pero rápidamente, desque vieron que non se podian defender, pleytearon con el rey [Enrique], e fincaron con todo lo suyo, e en su merced salvos e seguros, a cambio de un nuevo tributo de un millón de maravedíes ${ }^{58}$.

53. En este sentido Pedro I no hace más que reflotar el proyecto monárquico que Alfonso X había intentado llevar adelante a mediados del siglo XIII.

54. Como el caso de la judería de Toledo en 1355, relatado por LóPEZ de Ayala, P., Crónicas, edición de J. LuIs Martín, Planeta, Barcelona, 1991, p. 146.

55. Ayala, P. 239.

56. Ayala, P. 320

57. Ayala, P. 322

58. Ayala, P. 402. 
En efecto, la reconstitución del tejido social dañado por una guerra intermitente de más de una década y media de duración, no podía basarse en una suerte de política facciosa cuya única cualidad fuera ser la imagen especular de la del bloque derrotado. Tanto durante la guerra como en los años inmediatamente posteriores a su asunción como Enrique II, éste se esfuerza por dar una imagen de ecuanimidad, equilibrio y mesura, siempre dispuesto a ser indulgente con los antiguos aliados de Pedro y a satisfacer las demandas que éste había relegado, cuando no directamente despreciado. Tensionada entre la doble necesidad de responder a las demandas de los sectores que lo habían llevado al poder, y de recomponer los compromisos que ataban a los distintos actores al poder regio, la reconstrucción del equilibrio que lleva a cabo la nueva dinastía de los Trastámara no estará exenta, sin embargo, de violentos altibajos.

Observemos la evolución de estas fricciones. Tras auto-coronarse en 1367 (dos años antes de la derrota definitiva de su rival), Enrique convoca a Cortes en las que inevitablemente aparece el tema del endeudamiento. El argumento de los procuradores es sintomático de la situación política: declaran que los cristianos están muy empobrecidos por los grandes pechos e tributos queles fazia pagar aquel malo tirano que se llamaua Rey, e por aquellas companas estranas que venieron connusco [con Enrique] en nuestro seruiçio, por quanto ffizieron muchos rrobos $^{59}$. La primera parte de la declaración es obviamente un reconocimiento de la legitimidad del bando enriqueño, en su lucha contra un tirano que recaudaba tributos desmesurados sin siquiera convocar a los procuradores para recibir sus demandas, aunque también puede leerse como una advertencia velada al nuevo monarca: se espera de él un comportamiento distinto, una reconstitución del vínculo negociador entre la Corona y los representantes pecheros. Por otro lado, la referencia a los estragos causados por las tropas mercenarias francesas que le dieron el triunfo a Enrique, sin cuestionar a éste explícitamente, lo responsabiliza de forma indirecta de la pobreza de los campesinos, obligándolo a una reparación efectiva. Los procuradores piden, concretamente, una quita de la mitad de las deudas y una espera de 3 años para pagar el resto, demanda importante aunque no novedosa ${ }^{60}$. El monarca otorga una reducción de un tercio, y que el resto se pague por mitades en 2 años, período en el cual no se contarán intereses. Se ve aquí cómo el nuevo rey trata de volver al modelo de negociación de la primera mitad del siglo: otorgar menos de lo que se le pide, pero otorgar algo (de hecho, bastante: sumando la quita y la espera es la mayor concesión que registran los documentos de todo el siglo XIV). Atemperando la campaña propagandística anti-

59. Cortes, II, 1367, pet. 2.

60. Demanda similar habían realizado en 1329; véase supra. 
judía que tanto le había servido durante la guerra civil, Enrique intenta al mismo tiempo reconstituir el vínculo con los financistas judíos, de cuyos servicios no puede prescindir. Ante las quejas de los procuradores, reconoce haber arrendado las rentas de las ciudades a judíos por que non ffallamos otros algunos quela tomassen, aunque como buen rey, protector de los verdaderos creyentes, se declara dispuesto a dar el arrendamiento por mucho menos dela quantia por quela tienen arrendada los judios a cualquier cristiano que así lo desee: el saldo entre el perjuicio económico y el beneficio simbólico es sin duda positivo ${ }^{61}$.

Pero en 1367 Enrique no es todavía dueño de la situación; sólo el asesinato de Pedro dos años más tarde pone fin al enfrentamiento y lo consolida en el trono. La nueva situación se refleja en las cortes de 1369: ante el pedido de espera de las deudas formulado por los procuradores, el rey responde que los judíos estan pobres e menesterosos, por quanto non an cobrado ninguna cosa delo suyo de grant tiempo acá; otorga entonces un plazo de sólo dos meses para el pago de las obligaciones, con el agravante de que los que no paguen en término no puedan gozar de la quita otorgada en $1367^{62}$. El cambio de actitud es evidente: el compromiso del monarca con los procuradores, claramente expresado en la convocatoria periódica a Cortes, no debe impedirle al primero mantener una posición ecuánime con los sectores enfrentados por el problema de las deudas (su política pierde esta pretendida imparcialidad, sin embargo, frente a la nobleza, principal sostén del nuevo régimen: las desmesuradas concesiones de feudos con las que gratifica a los linajes que sostuvieron su causa serán motivo de queja frecuente por parte de los procuradores). Relativamente estabilizado en el poder, Enrique intenta desplazarse progresivamente hacia un punto de mayor equilibrio, que le permita recomponer las obligaciones recíprocas que ligan a todos los sectores sociales al poder central.

Pero la reconstitución del equilibrio no se garantiza por la sola actitud del nuevo monarca. La situación socioeconómica dista mucho de haber mejorado. La brusca devaluación monetaria de 1369, forma apenas velada de obtener los ingresos necesarios para pagar a los mercenarios franceses, provoca un inmediato descalabro en el conjunto de la economía ${ }^{63}$. La enajenación de importantes feudos y rentas regias en favor de la nobleza, el incremento de los tributos, los trastornos climáticos y las recurrentes mortandades o epidemias, confirman el carácter extremo de la situación. En este contexto, los procuradores retoman los argumentos de la campaña anti-judía realizada por Enrique durante el conflicto

61. Cortes, II, 1367, pet. 11

62. Cortes, II, 1369, pet. 68 .

63. Como se refleja en la tasa general de precios y salarios que el monarca se ve obligado a implementar en Cortes, II, 1369 , pet. 28 a 60 
bélico, como forma de expresar su descontento con la situación pero evitando al mismo tiempo cuestionar directamente al poder regio. Desde comienzos de la década del 70, la radicalización del discurso de los procuradores constituye una presión creciente, frente a la cual el monarca finalmente deberá ceder, al menos en parte.

La violenta ofensiva de los representantes pecheros, dispuestos a impedir el giro moderado del rey ya visible en 1369, comienza en las Cortes de 1371. En la segunda petición que presentan se quejan por los grandes ofiçios e onrras que y auian los judíos, la grand soltura e poderio que era dado alos enemigos dela fe, y denuncian que los cristianos se encuentran catiuos e sogeptos por ellos, pues deben obedecerles dado el lugar que ocupan en las casas señoriales e incluso en el entorno del rey; piden, en consecuencia, la aplicación efectiva de una serie de medidas discriminatorias ${ }^{64}$. La demanda es obviamente desmesurada y se corresponde menos con un incremento real de la influencia de los judíos que con la exacerbación del descontento popular. La frustrada esperanza de que Enrique desarrollara una política hostil hacia esa comunidad, en particular en lo referido al problema de las deudas, puede ayudar a entender lo que de otra forma parecería un brote de histeria. El rey, aunque implícitamente cuestionado en su carácter de protector de la comunidad cristiana, no se deja sin embargo intimidar, y responde sin demasiada preocupación que se guarde la normativa vigente en tiempos de su padre Alfonso XI. Similar actitud de distanciamiento refleja su respuesta ante el pedido de quita y espera que le realizan los procuradores: establece que en los 15 días siguientes a la finalización de las Cortes se paguen los dos tercios de los mondos adeudados, y si no que no haya reducción ninguna -medida de un carácter tan limitado que es casi, en la práctica, un rechazo de la solicitud de quita $^{65}$.

Pero el nuevo régimen no podrá mantener esta actitud distante por mucho tiempo. El peligro de perder una legitimidad tan costosamente obtenida, y aún relativamente precaria, lo obligará a sumergirse en el espiral anti-judío que su propia propaganda inicial había alentado. En cierto sentido, puede verse aquí una estrategia conciente. La relación de la Corona con las comunidades de realengo se va resintiendo progresivamente a medida que se profundizan la política pro-nobiliaria del régimen. La concesión de feudos y rentas a los señores deriva, además, en una lógica tendencia al incremento de los tributos en la jurisdicción regia (incluyendo mecanismos de extracción tales como las devaluaciones monetarias). Imposibilitado para revertir este favoritismo hacia la clase señorial y

64. Cortes, II, 1371, pet. 2.

65. Cortes, II, 1371, pet. 29. Sin embargo, a veces se toman medidas a nivel local: en Ledesma se decreta una espera de un año para las deudas con los judíos, Documentación... Ledesma, doc. 51, 18/12/1373. 
sus efectos negativos sobre el campesinado, el monarca parece dispuesto a congraciarse con los procuradores por la única vía que le queda disponible: ceder al sentimiento anti-judío y sacrificar en parte sus vínculos con esa comunidad.

Apremiado entonces por la presión de los reclamos concejiles, el monarca comienza a consentir en aspectos significativos. En 1377 se verifica un cambio sustancial. Luego de un año de epidemias, desastres climáticos y carestía, los procuradores realizan sus habituales denuncias: la pobreza de los cristianos los obligó a firmar cartas de muchas mayores quantias delo que rresçibieron, por lo que solicitan una reducción y moratoria. No es intrascendente, sin embargo, que revivan el argumento de que si agora lo ouiese a pagar, que se hermarian e non podrian conplir los pechos que han de pagar por nuestro seruiçio ${ }^{66}$. La acogida que da el rey a la demanda es llamativamente favorable. Repite aprobatoriamente los argumentos presentados en la petición sobre la miseria de los cristianos y los engaños de los judíos, y ordena una reducción de la tercera parte y una moratoria hasta el año siguiente. Como siempre, quien no pague en plazo no podrá gozar de la quita, pero al mismo tiempo se anulan las penas contenidas en los contratos -una medida que puede suponerse de alta repercusión, pues de hecho elimina las sanciones que obligan a la restitución del préstamo. Más significativo aún, en lo que hace al cambio de actitud del monarca, es que además no sólo se ratifica la prohibición total de prestar a interés contenida en el ordenamiento de Alcalá de 1348, sino que también, para evitar que se realicen contratos que consignan mayores quantias que las efectivamente prestadas, se prohíbe en forma total a judíos y moros hacer cartas de obligación de ningún tipo sobre los cristianos. Tales contratos pierden automáticamente valor legal, y el escribano que los avale será privado de su oficio ${ }^{67}$. La novedad es drástica, pues establece una condición de inferioridad jurídica sorprendente para las minorías religiosas ${ }^{68}$. El rey introduce, sin embargo, una cláusula significativa: quedan exceptuados de la prohibición los miembros de dichas comunidades que sean arrendadores de rentas regias. El compromiso del poder, por lo tanto, no desaparece por completo: se mantiene de forma selectiva con aquellos prestamistas que contribuyen directamente a la materialización del tributo feudal centralizado ${ }^{69}$. Éste es el último reducto que el monarca ha podido salvaguardar ante la ofensiva de los procuradores, reducto

66. Cortes, II, 1377, pet. 1.

67. Cortes, II, 1377 , pet. 2 y 3.

68. En las mismas cortes de menciona, por otro lado, que en el contexto de carestía también los cristianos dan a usura en forma de ventas fiadas de alimentos, lo que ratifica que la política regia está más destinada a responder al sentimiento xenófobo que a solucionar realmente el tema del endeudamiento campesino; Cortes, II, 1377, pet. 5 .

69. El concepto corresponde a Anderson, P., El Estado absolutista, Siglo XXI, México, 1979. 
que no está dispuesto a ceder porque forma parte de las condiciones de reproducción de su propio poder.

La situación se acerca a un punto límite que el sucesor de Enrique, su hijo Juan I, no podrá controlar. Tras la ratificación de rigor en 1379 del ordenamiento enriqueño recién analizado ${ }^{70}$, el nuevo monarca intenta durante la década del 80 volver a una posición de imparcialidad que no hará más que alejarlo progresivamente de los reclamos de los procuradores. Al mismo tiempo, la continuación del favoritismo regio hacia la nobleza irrita doblemente a estos últimos. Se preanuncia en esta divergencia creciente el proceso que culminará con las violentas jornadas de 1391.

La creciente tensión entre la Corona y los procuradores se evidencia en las Cortes de 1385. Los procuradores denuncian que la enajenación de feudos regios en beneficio de la nobleza conlleva múltiples abusos hacia los tributarios. En sus nuevas tierras, los señores auian echado muy grandes pedidos, e les han fecho muchas fuerças e muchos males e sin rrazones, por lo qual las dichas villas e logares sson destroydos e despoblados; a los que no pagan los encarcelan, asi commo a catiuos, y los obligan a sacar préstamos a usura, en manera que mientre biuan que nunca se podrian quitar. La evasiva respuesta regia (que va a fablar con los caualleros al respecto) no puede sino haber dejado insatisfechos a los procuradores, quienes comprueban de esta forma que el compromiso prioritario del monarca no es con ellos ${ }^{71}$. Luego responde, ante el pedido de quita y espera, que ya otorgó una reducción en las Cortes de Segovia de 1383, y que no puede hacerlo nuevamente porque los judíos non ternian con que nos seruir nin conplir los nuestros menesteres ${ }^{72}$. Más aún, cuando los procuradores piden que sean abolidos ciertos privilegios jurídicos de los judíos (que se les crea por su juramento, y que los contratos que los involucran deben hacerse con testigos de su comunidad), Juan I responde que esos privilegios se justifican porque se presume que los cristianos darán falso testimonio contra ellos por la enemistad grande que han con ellos ${ }^{73}$.

El evidente intento de volver a una posición de equilibrio en el conflicto entre tributarios y prestamistas, pero manteniendo el partidismo hacia la nobleza, resulta una estrategia cuya fragilidad se ve agravada por otros factores. A partir de 1386, el reino debe hacer frente a dos conflictos bélicos que provocarán una

70. Cortes, II, 1379, pet. 25.

71. Cortes, II, 1385, pet. 7; la denuncia se repite al año siguiente, lo cual indica que no se hizo nada al respecto, Cortes, II, 1386, pet. 16 .

72. Cortes, II, 1385, pet. 10; sabemos que las Cortes de Segovia se realizaron en 1383 gracias al relato de la crónica de Ayala, aunque no se ha conservado ningún cuaderno de ellas; AYALA, Crónicas, p. 548.

73. Cortes, II, 1385, pet. 11 y 12 . 
sustancial sangría de recursos. El primero de ellos se desata con el duque de Lancaster, yerno inglés del difunto Pedro I, que reclama por ese vínculo el trono de Castilla. Tras su desembarco en Galicia, los enfrentamientos culminarán con un acuerdo en que Juan I se compromete a pagar una sustancial suma de dinero a cambio de la renuncia del duque a sus pretensiones dinásticas. Al mismo tiempo, un conflicto sucesorio en Portugal despierta la ambición del monarca castellano, quien invade el reino vecino con el objeto de adicionarlo a sus dominios. Militarmente desastrosa, la operación culmina con una rápida y muy poco digna retirada, cuyo costo económico es sin embargo significativo: a los empréstitos pedidos a Francia y Navarra se agrega la necesidad de pagar a las tropas mercenarias contratadas.

En esta situación de crisis política y ahogo presupuestario, el rey debe pedir a las Cortes reunidas en 1387 el otorgamiento de un tributo o servicio extraordinario muy superior al de costumbre. Los procuradores lo otorgan, pero el clima de tensión de la reunión parece haber sido muy alto. Antes de aprobar el servicio, recuerdan al rey que sus gastos se financian de cuestas e sudores de labradores, y le exigen que en adelante no tenga la mano tan larga en dar commo fasta aqui, en obvia referencia a la reducción de los ingresos reales causada por su desmedida generosidad con la nobleza ${ }^{74}$. Piden además una rendición de cuentas de los gastos regios del año corriente ${ }^{75}$. Sólo tras estas agresivas declaraciones conceden el tributo extraordinario, de forma tal que el monarca se ve obligado no sólo a agradecer el otorgamiento del servicio, sino a aclarar también que sólo pide saluo aquello que nos fuese neçesario en tan crítica situación ${ }^{76}$.

Al mismo tiempo, Juan reconoce haber fabricado moneda de baja ley (es decir, de menor valor intrínseco que nominal), por lo que se ve obligado a decretar sucesivas devaluaciones, que contemplan mecanismos de actualización de los montos de las deudas pasadas, compensando en parte a los acreedores ${ }^{77}$. El descontento de los procuradores se expresa en las Cortes de 1388, donde señalan que los grandes pechos e seruiçios exigidos por el rey son la causa del endeudamiento campesino. El monarca concede una quita de un tercio, pero sólo para aquellos contratos hechos desde el año anterior en adelante ${ }^{78}$.

La situación desemboca entonces en los acontecimientos de 1391. Perjudicados por el crecimiento de los tributos, las devaluaciones monetarias y la guerra,

\footnotetext{
74. Cortes, II, 1387 , pet. 43 .

75. Ídem, pet. 45 .

76. Ídem, pet. 46 .

77. Cortes, II, 1387, «Ordenamiento sobre la baja de la moneda de los blancos», p. 359 y ss.

78. Cortes, II, 1388, pet. 6 .
} 
los pecheros observan con creciente irritación la relativa impermeabilidad del monarca frente a sus reclamos, por contraste con la disposición que muestra frente a las exigencias señoriales. En este contexto, la corriente anti-judía fomentada durante la guerra civil y en la década del 70 por Enrique II no podía más que crecer. Ideada originalmente por el poder como forma de legitimación ideológica, confluye con la insatisfacción de las necesidades campesinas y con la representación confesional del problema del endeudamiento, para trasformarse en una vía indirecta de manifestación del descontento popular. Por si no fuera suficiente, Juan I muere repentinamente en un accidente ecuestre en 1390, siendo su primogénito (el futuro Enrique III) menor de edad, lo cual abre un período de regencia signado por los conflictos facciosos entre los tutores y la consiguiente pérdida de legitimidad del poder monárquico.

El detonante de esta situación explosiva fue la prédica del arcediano de Écija, en Sevilla, sumado a la crisis de autoridad y a innegables motivos materiales: las gentes de los pueblos, lo uno por tales predicaciones, lo al por voluntad de robar, otrosí non aviendo miedo al rey por la edad pequeña que avía, e por la discordia que era entre los señores del reino... ${ }^{79}$. Coyunturalmente destrozados los vínculos sociales, se produce un violento levantamiento, que pierde fuerza a medida que se extiende hacia el norte del reino, consistente en ataques a las aljamas de los judíos, que son saqueadas y sus habitantes asesinados. Esta ruptura definitiva de lo que había sido un vínculo tenso pero en general pacífico, provoca la ruina de la comunidad agredida: bruscamente empobrecida por el saqueo, los que escapan a la muerte se convierten por temor masivamente al cristianismo ${ }^{80}$.

Culmina así de forma trágica un capítulo de un siglo y medio de conflictos en torno al problema de la «usura de los judíos». El precario equilibrio que la Corona había logrado mantener hasta entonces, basado en la satisfacción relativa de los compromisos que la ataban a los distintos sectores sociales, se rompe estrepitosamente con un baño de sangre que desnuda los intereses contradictorios subyacentes. Catorce años más tarde, casi por inercia, y nuevamente en una coyuntura de devaluación monetaria e inflación de precios, se establece en Cortes un nuevo ordenamiento sobre los judíos y la usura, por nos seruir a Dios enesto... e por tirar los dapnos que por esta rrazon viene a nuestro pueblo e alas nuestras tierras $^{81}$. Este será, sin embargo, el último acto jurídico significativo sobre el tema, hasta que a fines del siglo XV se plantee el problema de la conversión o expulsión de los judíos. En ese lapso de casi una centuria, el tema virtualmente desaparece

79. Ayala, Crónicas, p. 739. WolfF, Ph., «The 1391 Progrom in Spain. Social Crisis or Not?», en Past and Present, $\mathrm{N}^{\circ}$ 50, 1971, especialmente referido al desarrollo del conflicto en el ámbito aragonés.

80. Véase, por ejemplo, Colección... Cuenca, doc. 187, 15/5/1408.

81. Cortes, II, 1405, «Ordenamiento sobre los judíos y la usura», p. 544 y ss.; la cita en p. 546. 
de las Cortes $^{82}$. El cambio -que, como ya hemos indicado, coincide con la reversión de la prolongada coyuntura depresiva - tal vez pueda explicarse por una asimilación, fruto de la conversión forzada, de los prestamistas a la comunidad cristiana, y en especial al estrato superior de las comunidades, del cual también provienen los procuradores. Lo que sabemos con absoluta seguridad -porque así lo revela la documentación de las aldeas- es que en ese último siglo medieval la tendencia al endeudamiento de los campesinos no hace más que incrementarse. Pero tales hipótesis exceden los límites propuestos para este trabajo.

\section{COMENTARIOS FINALES}

El proceso de trabajosa negociación que hemos analizado muestra cómo los intereses contradictorios que están en la base de la relación de endeudamiento se canalizan, desde mediados del s. XIII hasta fines del s. XIV, en el marco del triple vínculo que une a la Corona, por un lado, con los procuradores (y a través de ellos, con los pecheros), por otro lado, con los prestamistas, y en tercer lugar, con la nobleza. El poder regio se encuentra de esta forma en la necesidad de balancear el conjunto de obligaciones que lo relacionan con las distintas clases sociales, balance cuyas proporciones precisas se establecen según las características concretas de cada coyuntura sociopolítica. La armonía es precaria, siempre amenazada por la capacidad de presión diferencial que ciertos sectores pueden adquirir en determinado contexto, y por las necesidades materiales y de legitimación, también contextuales, de la Corona. Las oscilaciones, sin embargo, no fueron hasta finales del siglo XIV tan bruscas como para impedir que la sumatoria de los compromisos sectoriales garantizara la reproducción estructural en el mediano plazo.

No fue la usura en sí misma (como creadora de algún tipo de «solidaridad» social) la que produjo este resultado, sino más bien el conjunto de los compromisos existentes que se pusieron en juego a la hora de negociar los términos de su reglamentación. Dicho de otra forma, no fue el endeudamiento el creador de la relación socialmente determinante, sino que más bien fue el vínculo social «total» y pre-existente el que se actualizó y modificó al calor de la negociación. La relación exclusivamente económica del préstamo pone en movimiento, de esta manera, un engranaje de complejas relaciones de clase, movimiento que se manifiesta en las estrategias negociadoras de los actores y que afecta a la totalidad del tejido social.

82. En Cortes, III, 1435, pet. 35, y 1438, pet. 10, aún se condena la barata o venta ficticia que encubre un préstamo, pero se pide al mismo tiempo que los judíos puedan hacer préstamos por un interés razonable. Por el contrario, se demandan medidas a favor de los acreedores en Cortes, III, 1462, pet. 23; 1473, pet. 30; Cortes, IV, 1476, pet. 11 y 36. 